\section{Which body mass index is best associated with risk of diabetes mellitus and hypertension in a Japanese-Brazilian population?}

\author{
Que valor de índice de massa corporal melhor \\ se associa a risco de diabetes mellitus e \\ hipertensão em nipo-brasileiros?
}

Rosana Farah Simony 1

Suely Godoy Agostinho Gimeno 1

Sandra Roberta Gouveia Ferreira 1

Laércio Joel Franco 2

Japanese-Brazilian Diabetes Study Group 3

\footnotetext{
${ }^{1}$ Escola Paulista de Medicina, Universidade Federal de São Paulo, São Paulo, Brasil. 2 Faculdade de Medicina de Ribeirão Preto, Universidade de São Paulo, Ribeirão Preto, Brasil. 3 Others members listed at the end of the paper.

Correspondence R. F. Simony Departamento de Medicina Preventiva, Escola Paulista de Medicina, Universidade Federal de São Paulo. Rua Zacarias de Gois 1326, apto. 131, Campo Belo, SP 04610-000, Brasil. rosanafarah@terra.com.br
}

\begin{abstract}
The objective of this study was to evaluate the impact of different body mass index (BMI) ranges associated with the risk of diabetes and hypertension in Japanese-Brazilians. This crosssectional study was based on data from 1,330 Japanese-Brazilians $\geq 30$ years of age who participated in a population-based survey on the prevalence of diabetes mellitus and associated diseases. Glucose tolerance status was classified according to WHO criteria and blood pressure levels according to the VI-JNC. Odds ratios for diabetes and hypertension were calculated for different BMI ranges; for different BMIs, sensitivity and specificity for percentiles 25, 50, 75, 90 and 95 were obtained. Increased odds ratios for diabetes mellitus and hypertension were observed with BMI values $\geq 25 \mathrm{~kg} / \mathrm{m}^{2}$. The 50 th percentile corresponded to the highest sensitivity and specificity for the identification of risk for both diseases. Our results suggest that BMI values proposed by WHO should also be useful for this group of Japanese descendants in the assessment of risk for DM and hypertension.
\end{abstract}

Diabetes Mellitus; Hypertension; Body Mass Index; Sensitivity and Specificity

\section{Introduction}

The definitions of overweight and obesity in adult individuals have varied over time 1 . The most commonly used indicator to evaluate excess body fat is body mass index (BMI) 1,2. Although this index has advantages in clinical and epidemiological practice - as a non-invasive and low-cost method - its predictive value for chronic diseases has been questioned, especially when applied to certain population groups $3,4,5$. In 1997 , the World Health Organization (WHO) ${ }^{6}$ proposed a criterion for classifying body fat based on $\mathrm{BMI}$, according to which individuals with $\mathrm{BMI} \geq$ $30 \mathrm{~kg} / \mathrm{m}^{2}$ are considered obese. However, in Western populations, obesity-related health problems are already observed in individuals with BMI $<30 \mathrm{~kg} / \mathrm{m}^{2} 7$, and some studies in Caucasians have shown increased risk of cardiovascular diseases with BMI values below $25 \mathrm{~kg} / \mathrm{m}^{2} 8$.

In Japan and other Asian countries, there has been an increase in the prevalence of excess weight in the last 20 years. Although Japanese individuals are generally considered non-obese when compared to Caucasians, an increase has been observed in the prevalence of diabetes mellitus and cardiovascular diseases among the former, even in the normal weight bracket under the WHO classification 9 . This has led some authors to suggest that the criterion proposed by WHO is not appropriate for Asian populations, since they present a distinct body build from Cauca- 
sians. The Japan Society for the Study of Obesity (JASSO) has proposed the use of BMI $23 \mathrm{~kg} / \mathrm{m}^{2}$ and $25 \mathrm{~kg} / \mathrm{m}^{2}$, respectively, as cutoff points for defining overweight and obesity in Japanese individuals 10 .

The current study aimed to evaluate the adequacy of the BMI cutoff points suggested by the JASSO, examining their sensitivity and specificity in the identification of individuals with diabetes mellitus and hypertension among individuals with pure Japanese ancestry.

\section{Methods}

The data used in the current study are from a cohort-type population study initiated in 1993, following a demographic survey, with the purpose of identifying the prevalence of diabetes mellitus (based on the oral glucose tolerance test) and associated diseases in first-generation JapaneseBrazilians (Issei, or born in Japan) and secondgeneration (Nisei, or born in Brazil) from 40 to 79 years of age, both males and females, residing in the municipality of Bauru, São Paulo. Details on the population selection, recruiting, and characteristics have been described elsewhere 11. This phase of the study showed an elevated risk of these individuals developing chronic noncommunicable diseases, particularly diabetes mellitus 12,13. Thus, in 2000 a second phase of the research was launched, using a cross-sectional design like the first. The current analyses refer to the second phase, in which all first - and secondgeneration Japanese-Brazilians $\geq 30$ years of age ( $n=1,751)$ were invited to participate, of whom $1,330(76 \%)$ were examined at the Labio-Facial Rehabilitation Hospital in Bauru. Reasons for non-participation were: death (before or during the field work, $n=94 ; 22.3 \%$ ), change of address $(\mathrm{n}=57 ; 13.5 \%)$, and refusal $(\mathrm{n}=270 ; 64.2 \%)$. Those who did not participate in the study showed a higher proportion of males $\leq 60$ years as compared to participants.

The first contact was by telephone, when the study objectives were explained. After agreeing to participate in the study (previously approved by the Research Ethics Committee at the Federal University in São Paulo), participants signed a free informed consent form and were interviewed at their homes by trained personnel, using standardized, previously tested questionnaires to obtain data on socio-demographics (sex, age, and generation), health, and eating habits, and the participants were scheduled for clinical examination and lab tests after ten hours fasting.

During physical examination by physicians, weight and height were measured with subjects wearing light clothing and no shoes, using a calibrated digital anthropometric scale (Filizola) and a stadiometer attached to the wall, respectively.

BMI was calculated by dividing weight (in kilos) squared by height (in meters). Since there were few individuals with $\mathrm{BMI} \geq 33 \mathrm{~kg} / \mathrm{m}^{2}(\mathrm{n}=46$; $3 \%$ ), these were grouped in the same category, without differentiating between levels of obesity, in order to allow the data analysis.

Arterial pressure was measured by the auscultation method, using an automatic sphygmomanometer (Omron model HEM-712C, Omron Health Care Incorporation, USA) and adjusting the cuff to the arm circumference after ten minutes resting in sitting position. Three measurements were taken, and the final value was that representing the mean of the last two measurements. Arterial hypertension was defined according to the seventh report of the Joint National Committee 14 (systolic arterial pressure $\geq$ $140 \mathrm{mmHg}$ or diastolic $\geq 90 \mathrm{mmHg}$ ) or use of antihypertensive medication.

Subjects were submitted to the oral glucose tolerance test $(75 \mathrm{~g})$ and other biochemical and hormone tests. For the purposes of this study, the focus will be on blood glucose levels (fasting and 2 hours post-overload) and lipid profile. Glucose tolerance status was classified according to WHO guidelines 15 , and diabetes was defined as fasting blood glucose $\geq 126 \mathrm{mg} / \mathrm{dl}$ and/or twohours post-overload glucose $\geq 200 \mathrm{mg} / \mathrm{dl}$ or use of anti-diabetic medication. Blood glucose was measured by the glucose-oxidase method.

\section{Statistics}

The logistic regression model was used to obtain odds ratios for different BMI values, adjusting for sex, age, and generation, in order to identify possible associations with diabetes mellitus and hypertension. The BMI $<20 \mathrm{~kg} / \mathrm{m}^{2}$ reference category was adopted. Also calculated were the sensitivity, specificity, and percentage of individuals correctly classified for BMI values according to percentiles $25,50,75,90$, and 95 , as well as the percentage of individuals correctly classified for presence of the target diseases. The values for the ROC (receiver operating characteristic) curve were used to describe the accuracy of BMI for identifying individuals with diabetes mellitus and hypertension, and the predictive capacity increased with the area (maximum value $=1$ ) 16 . Since diabetes mellitus and hypertension tend to improve with weight correction, the present study excluded individuals with prior diagnosis of the target diseases (145 diabetics and 309 hypertensives), in order to minimize the presence of a possible bias, since these individuals might 
be on some diet control, which could lead to a decrease in body weight.

The data analysis used Stata Statistical Software, version 7.0 (Stata Corporation, College Station, USA).

\section{Results}

The study population consisted of $46.1 \%$ males and $53.9 \%$ females, with mean age 57 years; $19.5 \%$ and $80.5 \%$, respectively, were first- and second-generation Japanese-Brazilian.

According to generation, analysis of the associations with diabetes mellitus and hypertension and different BMI ranges (Tables 1 and 2) showed that the odds ratios increased proportionally with increasing BMI, especially for hypertension. However, the odds ratios only became statistically significant with $B M I \geq 25.0 \mathrm{~kg} / \mathrm{m}^{2}$. The strata with large confidence intervals were due to the small number of individuals in these categories.

Table 3 shows the sensitivity and specificity of the BMI values and the percentage of individuals correctly classified for the target diseases. As expected, the sensitivity decreased and specificity increased as the BMI values increased. The BMI values with the best combination of sensitivity and specificity to predict diabetes mellitus and hypertension in Japanese-Brazilians of both genders varied from 24.1 to $24.6 \mathrm{~kg} / \mathrm{m}^{2}$.

The ROC curve areas were 0.67 and 0.58 , respectively, for diabetes mellitus and hypertension, suggesting that they have a moderate "predictive" capacity.

Figures 1 and 2 shows the risk of diabetes mellitus and arterial hypertension for each BMI value, confirming an increased risk of these diseases with increasing BMI.

\section{Discussion}

Characteristics proper to different population groups can mean that individuals with the same BMI values can present different body build. In particular, Japanese tend to be short with have a long body trunk, and obesity is not typical, unlike in the North American population 17. This leads to the supposition that different criteria should be employed to evaluate body fat in different population groups. There is no consensus in the literature concerning the universal application of anthropometric cutoff points for this purpose 18 . The current study adds data on the need (or lack thereof) in Japanese-descendant individuals to adjust the BMI values for indicating increased odds of two important diseases, diabetes mellitus

Odds ratios of diabetes mellitus for different body mass index (BMI) ranges in Japanese-Brazilians.

\begin{tabular}{|c|c|c|c|c|}
\hline \multirow[t]{3}{*}{ BMI ranges $\left(\mathrm{kg} / \mathrm{m}^{2}\right)$} & \multicolumn{4}{|c|}{ Diabetes mellitus } \\
\hline & \multirow[t]{2}{*}{$\mathbf{n}$} & $\%$ & Odds ratio & $p$-value \\
\hline & & \multicolumn{3}{|c|}{$(95 \% \mathrm{Cl})^{*}$} \\
\hline$\leq 20.0$ & 73 & 8.1 & 1.00 & \\
\hline 20.0-20.9 & 41 & 4.6 & $0.75(0.39-1.43)$ & 0.38 \\
\hline $21.0-21.9$ & 61 & 6.8 & $1.04(0.57-1.90)$ & 0.90 \\
\hline $22.0-22.9$ & 80 & 8.9 & $1.09(0.62-1.93)$ & 0.76 \\
\hline $23.0-23.9$ & 97 & 10.8 & $1.36(0.77-2.40)$ & 0.29 \\
\hline $24.0-24.9$ & 98 & 10.9 & $1.52(0.90-2.90)$ & 0.10 \\
\hline $25.0-25.9$ & 93 & 10.3 & $2.03(1.08-3.80)$ & 0.03 \\
\hline $26.0-26.9$ & 89 & 9.9 & $2.70(1.39-5.25)$ & 0.03 \\
\hline $27.0-27.9$ & 72 & 7.9 & $3.12(1.50-6.48)$ & 0.00 \\
\hline $28.0-28.9$ & 53 & 5.9 & $4.82(1.86-12.51)$ & 0.00 \\
\hline $29.0-29.9$ & 46 & 5.1 & $25.40(3.34-193.56)$ & 0.00 \\
\hline $30.0-30.9$ & 25 & 2.8 & $6.61(1.46-30.00)$ & 0.00 \\
\hline $31.0-31.9$ & 19 & 2.1 & $6.52(1.40-30.30)$ & 0.01 \\
\hline $32.0-32.9$ & 19 & 2.1 & $5.16(1.10-24.14)$ & 0.02 \\
\hline$\geq 33.0$ & 36 & 4.0 & $20.12(2.62-154.37)$ & 0.04 \\
\hline Total & 902 & 100.0 & & \\
\hline
\end{tabular}

* Adjusted for sex, age, and generation. 
Odds ratios of arterial hypertension for different body mass index (BMI) ranges in Japanese-Brazilians.

\begin{tabular}{|c|c|c|c|c|}
\hline \multirow[t]{2}{*}{ BMI ranges $\left(\mathrm{kg} / \mathrm{m}^{2}\right)$} & \multicolumn{4}{|c|}{ Arterial hypertension } \\
\hline & $\mathrm{n}$ & $\%$ & $\begin{array}{l}\text { Odds ratio } \\
(95 \% \mathrm{Cl})^{\star}\end{array}$ & p-value \\
\hline$\leq 20.0$ & 20 & 7.2 & 1.00 & \\
\hline $20.0-20.9$ & 12 & 4.2 & $1.09(0.46-2.56)$ & 0.85 \\
\hline $21.0-21.9$ & 24 & 8.4 & $1.93(0.89-3.73)$ & 0.10 \\
\hline $22.0-22.9$ & 30 & 10.5 & $1.92(0.97-3.76)$ & 0.06 \\
\hline $23.0-23.9$ & 27 & 9.5 & $1.47(0.74-2.90)$ & 0.27 \\
\hline $24.0-24.9$ & 25 & 8.8 & $1.45(0.72-2.89)$ & 0.30 \\
\hline $25.0-25.9$ & 37 & 12.9 & $3.10(1.58-6.05)$ & 0.01 \\
\hline $26.0-26.9$ & 34 & 11.9 & $3.81(1.91-7.59)$ & 0.00 \\
\hline $27.0-27.9$ & 24 & 8.4 & $3.12(1.50-6.46)$ & 0.00 \\
\hline $28.0-28.9$ & 16 & 5.6 & $3.13(1.38-7.09)$ & 0.00 \\
\hline $29.0-29.9$ & 14 & 4.9 & $4.03(1.70-9.56)$ & 0.00 \\
\hline $30.0-30.9$ & 6 & 2.1 & $2.46(0.81-7.45)$ & 0.11 \\
\hline $31.0-31.9$ & 4 & 1.4 & $4.28(1.08-16.95)$ & 0.04 \\
\hline $32.0-32.9$ & 5 & 1.8 & $4.38(1.20-15.89)$ & 0.02 \\
\hline$\geq 33.0$ & 7 & 2.5 & $3.17(1.03-9.78)$ & 0.04 \\
\hline Total & 285 & 100.0 & & \\
\hline
\end{tabular}

* Adjusted for sex, age, and generation.

Sensitivity, specificity, and percentage of individuals correctly classified, using specific cutoff points for body mass index (BMI), according to presence of diabetes mellitus and arterial hypertension in Japanese-Brazilians.

\begin{tabular}{|c|c|c|c|c|c|}
\hline & Percentile & $\begin{array}{c}\text { BMI value } \\
\left(\mathrm{kg} / \mathrm{m}^{2}\right)\end{array}$ & $\begin{array}{c}\text { Sensitivity * } \\
\text { (\%) }\end{array}$ & $\begin{array}{c}\text { Specificity * } \\
\text { (\%) }\end{array}$ & $\begin{array}{l}\text { Individuals } \\
\text { correctly } \\
\text { classified (\%) }\end{array}$ \\
\hline Presence of & 25 & 22.4 & 87.1 & 38.6 & 64.9 \\
\hline \multirow[t]{3}{*}{ diabetes mellitus } & 50 & 24.6 & 68.2 & 70.4 & 69.2 \\
\hline & 75 & 27.2 & 39.0 & 91.8 & 63.1 \\
\hline & 95 & 32.2 & 8.1 & 98.9 & 49.6 \\
\hline Presence of & 25 & 21.9 & 80.8 & 26.3 & 24.2 \\
\hline arterial & 50 & 24.1 & 60.5 & 53.8 & 27.3 \\
\hline \multirow[t]{2}{*}{ hypertension } & 75 & 26.6 & 33.2 & 78.3 & 31.2 \\
\hline & 95 & 30.6 & 6.3 & 95.5 & 37.8 \\
\hline
\end{tabular}

* Adjusted for sex, age, and generation.

and hypertension, with high prevalence among Japanese-Brazilians 19, both of which increase cardiovascular mortality 11 .

As observed in Caucasians, among both male and female Japanese-Brazilians, the associations between BMI and diabetes mellitus and hypertension were statistically significant with $\mathrm{BMI} \geq$ $25 \mathrm{~kg} / \mathrm{m}^{2}$, a value that WHO 6 sets as the upper limit for normal weight.
Similar results were found in a study of 1,193 Japanese adults residing in Japan 7 , in which the authors observed that BMI of $25 \mathrm{~kg} / \mathrm{m}^{2}$ showed the best sensitivity and specificity for identifying individuals with obesity. Recently, McNeely 20 showed that in Japanese-Americans the risk of developing diabetes mellitus was greater for $\mathrm{BMI} \geq 25 \mathrm{~kg} / \mathrm{m}^{2}$, suggesting the use of this value as the cutoff. 
Figure 1

Sensitivity and specificity of body mass index (BMI) values according to presence of diabetes mellitus.

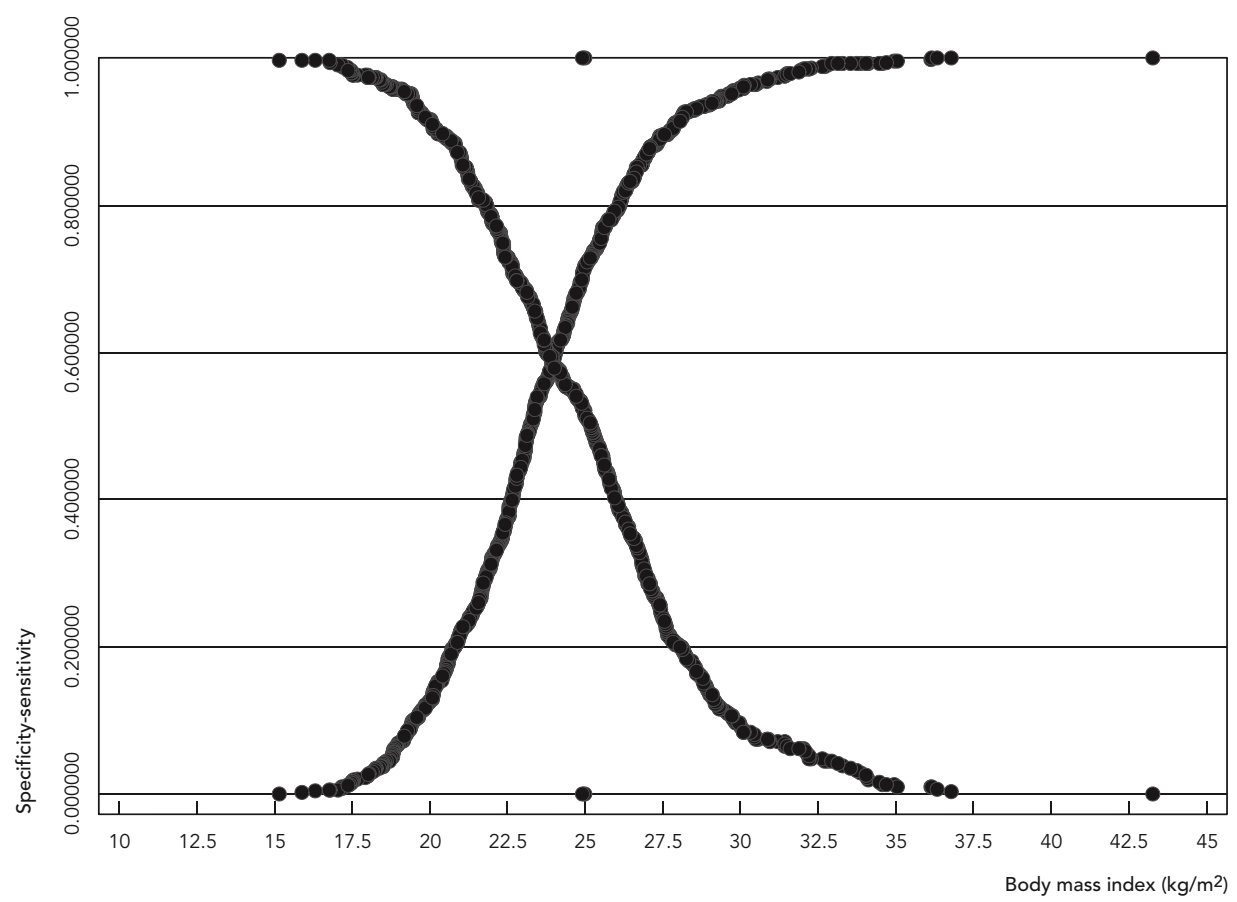

Figure 2

Sensitivity and specificity of body mass index (BMI) values according to presence of arterial hypertension.




However, some studies in the literature disagree with these results, suggesting cutoff points for overweight and obesity that are different from those used for Western populations. One example is a publication on anthropometry in Asian populations 21 , which would already classify Asians with $\mathrm{BMI} \geq 23.0 \mathrm{~kg} / \mathrm{m}^{2}$ as overweight and $\geq 25.0 \mathrm{~kg} / \mathrm{m}^{2}$ as obese.

According to Matsuzawa et al. 22, BMI < $22.2 \mathrm{~kg} / \mathrm{m}^{2}$ for men and $<21.9 \mathrm{~kg} / \mathrm{m}^{2}$ for women was associated with low morbidity in the Japanese adult population, proposing that the ideal weight for this population group use the formula: ideal weight $=22 \times$ height $^{2}$. Based on this same formula, Tokunaga et al. 23 proposed BMI $\geq 26.4 \mathrm{~kg} / \mathrm{m}^{2}$ as the criterion for obesity, which is currently accepted by the JASSO.

Ishikawa-Tanaka et al. ${ }^{24}$, examining the effects of different BMI and weight gain values associated with the risks of hypertension, hypercholesterolemia, and diabetes mellitus in Japanese men, concluded that for this population group with low prevalence of severe obesity, the best preventive measures for these diseases would be maintaining BMI between 18.5 and $25.0 \mathrm{~kg} / \mathrm{m}^{2}$ and avoiding weight gain greater than $2 \mathrm{~kg}$ in a four-year period. Based on our findings, these guidelines are also applicable to JapaneseBrazilians.

Ko et al. 25, in a study of workers in Hong Kong, observed that for the same BMI values, the risk of developing diabetes mellitus and hypertension was consistently greater in Chinese as compared to Caucasians, although our study design did not allow this type of comparison between Japanese-Brazilians and the overall Brazilian population.

The association between anthropometric values and risk of diabetes mellitus was also investigated in Japanese descendents residing in the United States 20, and Japanese-Americans $\leq$ 55 years of age with $\mathrm{BMI} \geq 27.6 \mathrm{~kg} / \mathrm{m}^{2}$ showed increased risk of developing diabetes mellitus.

Care should be taken in defining cutoff points for anthropometric variables (BMI, waist circumference) for different population groups, and ideally the criteria should be set based on the morbidity and mortality risks, since changes in the cutoff points can have significant implications for health systems. In the study by DeurenbergYap et al. 26 on health risks in Singapore, a decrease in the BMI cutoff for obesity from $30 \mathrm{~kg} / \mathrm{m}^{2}$ to $27 \mathrm{~kg} / \mathrm{m}^{2}$ would increase the prevalence of this disease from $6 \%$ to $16 \%$, which would have an enormous impact on public health policies in that country.

Considering the high prevalence of metabolic syndrome in Japanese-Brazilians 27, preventive measures are necessary for this population, including combating excess weight. This suggestion is backed by Yoshiike et al. ${ }^{28}$, indicating the need to develop specific strategies for the primary prevention of these diseases with obesity as a risk factor. In 2002, these authors highlighted the high prevalence rates of overweight in Japanese women (15\%) and men (21\%), which should be combated along with obesity.

In order to minimize possible classification errors in health and nutritional status, the current study opted to: (1) exclude individuals with prior diagnosis of the target diseases; (2) have the data collected by trained professionals; (3) use standard techniques for collection and analysis of biological material; and (4) use continuous data quality control. One cannot rule out the possibility of bias in the results, due to the percentage of individuals not examined (24\%); still, due to their similar demographic characteristics, one can suppose that the inclusion of these Japanese-Brazilians in the study would not have altered the results.

Prospective studies are known to be recommended to evaluate the risk of developing diseases in a population, but in the absence of data allowing a longitudinal analysis, a cross-sectional design was chosen for the available data, taking some methodological precautions. As mentioned above, individuals with prior diagnosis of target diseases were excluded, but it should be noted that individuals with other diseases, like dyslipidemia, in which weight loss is also indicated for clinical improvement, may have been included in the study, thereby altering the results. However, such individuals may have been situated in the excess weight categories, further reinforcing the use of the BMI $\geq 25 \mathrm{~kg} / \mathrm{m}^{2}$ cutoff point and the application of lower values in this population group. Another limitation of the present study was having considered only overall obesity (assessed by BMI) and not abdominal obesity (measured by waist circumference), which is known to bear a close relationship with the target diseases. This indicator of nutritional status is particularly important in Japanese-Brazilians, in whom prevalence of obesity (BMI $\geq 30 \mathrm{~kg} / \mathrm{m}^{2}$ ) is proven to be low 7 . Thus, future studies should be done with this population group, evaluating both overall and abdominal obesity in order to identify the risk among individuals with central adiposity alone.

Finally, although the present study was not able to establish causal relations or define normal BMI values, i.e., those related to low morbidity and mortality in general, the results showed that the BMI values with the best sensitivity and specificity for identifying individuals with diabetes mellitus and arterial hypertension are very 
close to the WHO guidelines 6 , suggesting that there is no need to adapt the BMI cutoff points for excess weight in this population group, but to focus greater attention on Japanese-Brazilians with $\mathrm{BMI} \geq 25 \mathrm{~kg} / \mathrm{m}^{2}$ in order to decrease the risk of developing diabetes mellitus and hyperten- sion associated with obesity. Prospective studies should be done to identify the causes of the incidence of these diseases and explain the role of genetic, nutritional, and/or metabolic factors in the appearance of these diseases in JapaneseBrazilians.

\section{Resumo}

Avaliou-se o impacto de diferentes valores de índice de massa corporal (IMC) associados ao risco de diabetes e hipertensão em descendentes japoneses. Este estudo transversal foi realizado com 1.330 nipo-brasileiros $\geq$ 30 anos, participantes de pesquisa populacional sobre prevalência de diabetes mellitus e doenças associadas. Para classificação da tolerância à glicose utilizou-se o critério da OMS e dos níveis pressóricos o do JNC-VI. Para diferentes faixas de IMC foram estimados os odds ratios para diabetes e hipertensão e obtidos os valores de sensibilidade e especificidade referentes aos percentis 25, 50, 75, 90 e 95. Observou-se que o aumento dos valores de odds ratio para o diabetes e hipertensão foi a partir do IMC $\geq 25 \mathrm{~kg} / \mathrm{m}^{2}$, sendo que o percentil 50 apresentou os melhores valores de sensibilidade e especificidade para ambas as doenças. Apesar dos nipobrasileiros apresentarem estrutura corporal diferente dos caucasianos, os resultados sugerem que os valores de IMC preconizados pela OMS podem ser aplicáveis também a este grupo de descendentes japoneses em estudos de associação de diabetes e hipertensão.

Diabetes Mellitus; Hipertensão; Índice de Massa Corporal; Sensibilidade e Especificidade

\section{Contributors}

R. F. Simony and S. G. A. Gimeno participated in the study design and statistical analysis. S. R. G. Ferreira participated in the manuscript review. L. J. Franco participated in the study design and manuscript review.

\section{Others members of the Japanese-Brazilian Diabetes Study Group}

N. Barros Jr., M. A. Cardoso, R. Chaim, S. R. G. Ferreira, L. J. Franco, S. G. A. Gimeno, H. Harima, A. Hirai, A. Hirai, L. Matsumura, R. S. Moisés, K. Osiro, N. Tomita, K. Wakisaka.

\section{Acknowledgments}

This study was conducted with funding from the Fundação de Amparo à Pesquisa do Estado de São Paulo (grant 00/01162-4). 


\section{References}

1. Deurenberg P, Deurenberg Yap M, Wang J, Lin FP, Schmidt G. The impact of body build on the relationship between body mass index and percent body fat. Int J Obes Relat Metab Disord 1999; 23:537-42.

2. World Health Organization. Obesity: preventing and managing the global epidemic. Geneva: World Health Organization; 2000. (Technical Report Series, 894)

3. Hubbard VS. Defining overweight and obesity: what issues? Am J Clin Nutr 2002; 72:1067-8.

4. Ko GTC, Tang J, Chan JCN, Wu MMF, Wai HPS, Chen R. Lower body mass index cut-off value to define obesity in Hong Kong Chinese: an analysis based on body fat assessment by bioeletrical impedance. Br J Nutr 2001; 85:239-42.

5. Long AE, Prewitt TE, Kaufman JS, Rotimi CN, Cooper RS, McGee DL. Weight-height relationships among eight populations of West African origin: the case against constant BMI standards. Int J Obes Relat Metab Disord 1998; 22:842-6.

6. World Health Organization. Physical status: the use and interpretation of anthropometry. Geneva: World Health Organization; 1995. (Technical Report Series, 854).

7. Japan Society for the Study of Obesity. New criteria for "Obesity Disease" in Japan. Circ J 2002; 66: 987-92.

8. Rexrode KM, Carey VJ, Hennekens CH, Walters EE, Colditz GA, Stampfer MJ, et al. Abdominal obesity and coronary heart disease in women. JAMA 1998; 280:1843-8.

9. Ota T, Takamura T, Hirai N, Kobayashi K. Preobesity in World Health Organization classification involves the metabolic syndrome in Japanese. Diabetes Care 2002; 25:1252-3.

10. Shiwaku K, Anuurad E, Enkhmaa B, Nogi A, Shimono K, Yamane Y, et al. Overweight Japanese with body mass indexes of 23.0-24.9 have higher risks for obesity-associated disorders: a comparison of Japanese and Mongolians. Int J Obes 2004; 28: 152-8.

11. Gimeno SGA, Ferreira SRG, Franco LJ, Iunes M, Osiro K. Incremento na mortalidade associada à presença de diabetes mellitus em nipo-brasileiros. Rev Saúde Pública 1998; 32:118-24.

12. Ferreira SRG, Iunes M, Franco LJ, Iochida LC, Hirai A, Vivolo MA. Disturbances of glucose and lipid metabolism in first and second generation Japanese-Brazilians. Diabetes Res Clin Pract 1996; 34 Suppl:S59-63.

13. Franco LJ. Diabetes in Japanese-Brazilians: influence of the acculturation process. Diabetes Res Clin Pract 1996; 34 Suppl:S51-7.

14. The sixth report of the Joint National Committee on prevention, detection, evaluation and treatment of high blood pressure. Arch Intern Med 1997; 157:2413-46.

15. Alberti KGMN, Zimmet PZ. Definition, diagnosis and classification of diabetes mellitus and its complications. Part 1: Diagnosis and classification of diabetes mellitus provisional. Report of a WHO Consultation WHO. Diabetes Med 1998; 15:539-53.
16. Fletcher RH, Fletcher SW, Wagner EH. Diagnóstico. In: Fletcher RH, Fletcher SW. Epidemiologia clínica. Porto Alegre: Editora Artes Médicas; 1991. p. 68-107.

17. Yanai M, Kumasaka K, Kawano K. Body mass index variations by age and sex, and prevalence of overweight in Japanese adults. Int J Obes 1997; 21: 484-8.

18. Deurenberg P. Universal cut-off BMI points for obesity are not appropriate. Br J Nutr 2001; 85: 135-6.

19. Gimeno SGA, Ferreira SRG, Franco LJ, Hirai A, Matsumura L, Moises RCS, et al. Prevalence and 7-year incidence of type 2 diabetes mellitus in a Japanese-Brazilian population: an alarming public health problem. Diabetologia 2002; 45:1635-8.

20. McNeely MJ, Boyko EJ, Shofer JB, Newell-Morris L, Leonetti DL, Fujimoto WY. Standard definitions of overweight and central adiposity for determining diabetes risk in Japanese Americans. Am J Clin Nutr 2001; 74:101-7.

21. Inoue S, Zimmet P, Caterson I, Chunming C, Ikeda $\mathrm{Y}$, Khalid AK, et al. The Asia-Pacific perspective: redefining obesity and its treatment. Melbourne: Health Communication; 2000.

22. Matsuzawa Y, Tokunaga K, Kotani K, Keno Y, Kobayashi T, Tarui S. Simple estimation of ideal body weight from body mass index with the lowest morbidity. Diabetes Res Clin Pract 1990; 10 Suppl 1:159-64.

23. Tokunaga K, Matsuzawa Y, Kotani K, Keno Y, Kobatake T, Fujioka S, et al. Ideal body weight estimated from the body mass index with the lowest morbidity. Int J Obes Relat Metab Disord 1991; 15:1-5.

24. Ishikawa-Tanaka K, Ohta T, Moritaki K, Gotou T, Inoue S. Obesity, weight change and risks for hypertension, diabetes and hypercholesterolemia in Japanese men. Eur J Clin Nutr 2002; 56:601-7.

25. Ko GTC, Tang J, Chan JCN, Wu MMF, Wai HPS, Chen R. Lower body mass index cut-off value to define obesity in Hong Kong Chinese: an analysis based on body fat assessment by bioeletrical impedance. Br J Nutr 2001; 85:239-42.

26. Deurenberg YM, Schimidt G, van Staveren WA, Deurenberg P. The paradox of low body mass index and high body fat percent among Chinese, Malays and Indians in Singapore. Int J Obes Relat Metab Disord 2000; 24:1011-7.

27. Rosenbaum P, Gimeno SGA, Sanudo A, Franco LJ, Ferreira SRG; Japanese-Brazilian Diabetes Study Group. Analysis of criteria for metabolic syndrome in a population-based study of Japanese-Brazilians. Diabetes Obes Metab 2005; 7:352-9.

28. Yoshiike N, Seino F, Tajima S, Arai Y, Kawano M, Furuhata $\mathrm{T}$, et al. Twenty-year changes in the prevalence of overweight in Japanese adults: The National Nutrition Survey 1976-95. Obes Rev 2002; 3:183-90.

Submitted on $23 / \mathrm{Feb} / 2005$

Final version resubmitted on 17/Oct/2005

Approved on 21/Oct/2005 